\title{
Working memory and Stroop interference: An individual differences investigation
}

\author{
DEBRA L. LONG and CHANTEL S. PRAT \\ University of California, Davis, California
}

\begin{abstract}
We investigated the claim that individual differences in working-memory capacity reflect limitations on the ability to inhibit task-irrelevant information and/or to maintain activation in the face of distracting or interfering events. Specifically, we investigated whether high- and low-capacity individuals differed in their susceptibility to interference on the Stroop task and whether high-capacity individuals employed a strategy for minimizing Stroop interference. In Experiment 1, we found that high-capacity participants showed substantial interference when conflict trials were infrequent, but almost no interference when conflict trials were frequent. In contrast, low-capacity participants showed substantial interferenceirrespective of the proportion of conflict trials. In Experiment 2, we found that high-capacity participants experienced substantial negative priming, slow responses when the to-be-named color was the irrelevant word on the previous trial. We discuss these results and their implications for highcapacity individuals' ability to reduce Stroop interference in light of both inhibitory and noninhibitory accounts of negative priming.
\end{abstract}

Many cognitive tasks involve multiple steps; thus, task goals, task-relevant information, and the intermediate results of multiple processing steps must be readily available in memory. Working memory is the theoretical construct used to refer to the system that is responsible for maintaining such information. It is similar in some respects to an older construct, short-term memory (STM), in that both are memory systems consisting of elements activated above some threshold level. Working memory differs from STM, however, in its emphasis on processing. In addition to activated memory elements, working memory emphasizes the mechanisms or processes that control, regulate, and maintain the activation of task-relevant information (Baddeley \& Hitch, 1974; Cowan, 1988, 1995; Klapp, Marshburn, \& Lester, 1983).

The hallmark characteristic of working memory is its limited capacity. Although the existence of capacity limitations is uncontroversial, the factors responsible for the limitations vary from theory to theory. These factors include constraints on the amount of activation available to the working-memory system (Engle, Cantor, \& Carullo, 1992; Just \& Carpenter, 1992; Lovett, Reder, \& Lebiere, 1999), similarity-based interference (Schneider, 1999; Young \& Lewis, 1999), processing speed (Kieras, Meyer, Mueller, \& Seymour, 1999; Salthouse, 1996), lack of skill or knowledge for efficient encoding and retrieval (Ericsson \& Delaney, 1999; Ericsson \& Kintsch, 1995),

Correspondence should be addressed to D. L. Long, Department of Psychology, 1 Shields Avenue, University of California, Davis, CA 95616 (e-mail: dllong@ucdavis.edu).

- Accepted by previous editorial team and the ability to inhibit irrelevant information (Rosen \& Engle, 1998; Stoltzfus, Hasher, \& Zacks, 1996).

One method used to examine the nature of workingmemory limitations has been to investigate the relation between performance on working-memory tasks and performance on a variety of complex, skilled tasks, including language comprehension (Daneman \& Carpenter, 1980, 1983; King \& Just, 1991; MacDonald, Just, \& Carpenter, 1992; Pearlmutter \& MacDonald, 1995), complex learning (Engle, Carullo, \& Collins, 1991; Kyllonen \& Stephens, 1990; Shute, 1991), and reasoning (Engle, Tuholski, Laughlin, \& Conway, 1999; Kyllonen \& Christal, 1990). The advantage of studying capacity limitations in the context of complex tasks is that such tasks place the greatest demands on working memory; thus, individual differences in performance are likely to be quite large. The disadvantage, however, is that these tasks involve multiple component processes, some of which may be poorly understood. This can give rise to considerable difficulty in understanding exactly how capacity limitations relate to task performance.

Here, we sought to examine the relation between working-memory capacity and interference on the Stroop color-word test. Although the Stroop task is by no means a "simple" task, it has been studied for decades and, compared with many tasks (e.g., language comprehension, reasoning), is better understood. The Stroop task involves selectively attending to one feature of a stimulus, the color of a printed word, while ignoring another feature, the word that is named by the stimulus (e.g., saying "green" in response to the word red in green print). The prevailing account of Stroop interference is that word reading is an automatic process; thus, it is not easily inhibited (MacLeod, 1991; MacLeod \& Dunbar, 1988; Posner \& 
Snyder, 1975). Skilled readers process the meaning of the word despite explicit instructions not to do so.

The Stroop task seems particularly well suited for studying claims that individual differences in workingmemory capacity reflect limitations on the ability to inhibit task-irrelevant information and/or to maintain activation in the face of distracting or interfering events. Such claims play a central role in a view of working memory proposed by Engle and his colleagues (Conway \& Engle, 1994; Engle, Conway, Tuholski, \& Shisler, 1995; Engle, Kane, \& Tuholski, 1999; Engle, Tuholski, et al., 1999; Rosen \& Engle, 1997). According to their view, working memory is "a system of those long-term memory traces active above threshold, the procedures and skills necessary to achieve and maintain that activation, and limited-capacity, controlled attention" (Engle, Kane, \& Tuholski, 1999, p. 102). Controlled attention is involved in maintaining activation of task-relevant information, particularly in the presence of distraction or interference, and in inhibiting task-irrelevant information. The capacity of controlled attention is limited and is the primary source of individual differences in workingmemory capacity.

This view of working-memory limitations predicts a relation between individual differences in capacity and performance on tasks that either encourage or demand controlled attention. These include every day or laboratory tasks that involve (1) maintaining task goals and taskrelevant information in the face of interference, (2) resolving conflict among competing responses, (3) suppressing task-irrelevant information, (4) controlled monitoring for errors, and (5) strategic and systematic memory search (Engle et al., 1995; Engle, Kane, \& Tuholski, 1999).

The Stroop task involves several of the features described above; thus, it appears ideal for investigating the relation between working-memory capacity and the ability to inhibit or suppress task-irrelevant information. The following experiments were designed to address three related questions: (1) Are low-capacity individuals more vulnerable to Stroop interference than are high-capacity individuals? (2) Do high-capacity individuals have strategies for minimizing Stroop interference? (3) If so, do highcapacity individuals show flexibility in their use of such strategies, adopting them in situations in which they are most useful?

\section{EXPERIMENT 1}

Previous research suggests a link between workingmemory capacity and susceptibility to Stroop interference. Old adults (i.e., adults over the age of 60), who score poorly on measures of working-memory capacity, tend to exhibit more Stroop interference than do young adults (Cohn, Dustman, \& Bradford, 1984; Comalli, Wapner, \& Werner, 1962; Dulaney \& Rogers, 1994; Panek, Rush, \& Slade, 1984). Moreover, old adults differ from young adults in the effect of practice on the Stroop task. Dulaney and Rogers gave young and old adults extensive practice at color naming printed words. They found that both groups showed an overall reduction in interference; however, performance on a posttest in which participants were asked to read the printed words showed that young, but not old, adults developed a "reading suppression" strategy. Young adults, relative to old adults, showed difficulty reading the words after extensive practice at color naming, suggesting that, with practice, young adults learned to inhibit word reading (but see MacLeod, 1998, who found no effect of Stroop practice on word reading in young adults).

In the present study, we investigated the relation between performance on a test of working-memory capacity and Stroop interference in a group of young adults. Participants were given a modified version of Daneman and Carpenter's (1980) reading-span test as a measure of their working-memory capacity. They were then asked to name the colors of printed stimuli. We examined their performance on conflict trials (i.e., saying "green" in response to the word red in green print) compared with their performance on neutral trials (i.e., saying "green" in response to a row of Xs in green print). We examined whether individuals who performed poorly on the capacity test (low-span individuals) showed more Stroop interference than did individuals who performed well on the test (high-span individuals).

In addition to investigating differences in the susceptibility of high- and low-span individuals to Stroop interference, we also examined whether high-span individuals would minimize interference by adopting a reading suppression strategy. Our manipulation was based on a recent study of individual differences in suppression. Gernsbacher and Faust (1995) examined good and poor readers' ability to suppress the irrelevant meanings of ambiguous words. They manipulated the proportion of trials on which suppression was needed and found that readers were more likely to suppress irrelevant information when the proportion of conflict trials was high than when the proportion of such trials was low. In other words, readers suppressed irrelevant information when suppression had high utility. In the present experiment, participants received two blocks of trials. One block consisted of a small number of conflict trials interleaved among a large number of neutral trials. The other block consisted of a large number of conflict trials interleaved among a small number of neutral trials. To the extent that highspan individuals can employ a reading suppression strategy, they may be more likely to do so when suppression is required on many trials.

\section{Method}

Participants. The participants were 30 undergraduate psychology students who received course credit for their participation. All participants spoke English as their first language and none had a diagnosed reading or learning disability.

Materials. Two sets of stimuli were used. Conflict stimuli were color words (red, yellow, blue, and green). These words were printed in incongruent colors on a black background. The neutral stimulus was XXXXX printed in red, yellow, blue, or green. Two 
Table 1

Mean Response Times (RTs, in Milliseconds), Percent Errors (PEs), and Standard Deviations to Neutral and Conflict Trials in Experiment 1

\begin{tabular}{|c|c|c|c|c|c|c|}
\hline \multirow[b]{3}{*}{ Trial Type } & \multicolumn{6}{|c|}{ Working-Memory Span } \\
\hline & \multicolumn{3}{|c|}{ High } & \multicolumn{3}{|c|}{ Low } \\
\hline & RT & PE & $S D$ & RT & PE & $S D$ \\
\hline \multicolumn{7}{|c|}{ High-Proportion Condition } \\
\hline Neutral & 720 & 2.0 & 49.90 & 788 & 2.3 & 140.13 \\
\hline Conflict & 758 & 2.1 & 31.28 & 900 & 2.2 & 168.15 \\
\hline \multicolumn{7}{|l|}{ Difference } \\
\hline (Conflict - Neutral) & 38 & 0.1 & & 112 & -0.1 & \\
\hline \multicolumn{7}{|c|}{ Low-Proportion Condition } \\
\hline Neutral & 692 & 1.9 & 37.37 & 773 & 2.0 & 159.30 \\
\hline Conflict & 884 & 2.1 & 51.23 & 921 & 2.0 & 189.08 \\
\hline \multicolumn{7}{|l|}{ Difference } \\
\hline (Conflict - Neutral) & 192 & 0.2 & & 148 & 0.0 & \\
\hline
\end{tabular}

blocks of 100 trials were constructed. One block consisted of 20 conflict and 80 neutral trials (low-proportion condition); the other consisted of 80 neutral and 20 control trials (high-proportion condition). Colors and words appeared approximately equally often within each block. A separate block of 20 trials (10 conflict and 10 neutral) was constructed as a practice set.

All participants received a modified version of Daneman and Carpenter's (1980) reading-span task. The task consisted of a list of 60 unrelated, complex sentences. The sentences were presented one at a time and participants read the sentences aloud while trying to remember the last word of each sentence. Set size, the number of sentences presented before recall was tested, varied from two to six. Participants received three trials of each set size. In addition, participants received two set sizes as practice (one set size of two and one set size of four).

Procedure. The experiment was conducted in two sessions approximately $24 \mathrm{~h}$ apart. In the first session, participants performed the reading-span task. The sentences were presented one at a time in the center of a computer screen. Each participant received a different random order of sets and a different random order of trials within sets. Participants read each sentence aloud; the experimenter pressed a key when the participant read the final word of the sentence, and the next sentence appeared. After all of the sentences in a set had been presented, a prompt appeared on the screen directing participants to recall the words (i.e., "Recall the words now"). Participants recalled the words aloud and the experimenter typed them on the keyboard.

In Session 2, the Stroop task was administered to all participants. The order of blocks was counterbalanced so that half of the participants received the low-proportion block first and half received the high-proportion block first. To ensure that we had similar readingspan distributions in each counterbalancing condition, we used the following procedure. We scored the reading span test and ranked all participants according to their performance, from the highest to the lowest scoring participant. We then proceeded through the ranking, top to bottom, selecting pairs of participants. The first member of each pair was randomly assigned to one of the counterbalancing conditions; the second member of the pair was assigned to the other condition.

Participants received the practice trials first and then the two blocks of experimental trials. Trials were presented in a different random order for each participant. Participants received a 5-min break between blocks. Each stimulus appeared on the screen until a response was detected by means of a voice-activated relay. A 250 -msec blank screen followed the stimulus offset. All naming la- tencies were recorded. An experimenter observed the session and recorded all errors.

\section{Results and Discussion}

Reading span. High- and low-span participants were identified on the basis of their test performance (the top and bottom third of participants, respectively). Highspan individuals had scores that ranged from 39 to 50 $(M=43.4, n=10)$. Low-span individuals had scores that ranged from 15 to $29(M=24.0, n=10)$.

Stroop performance. All effects were tested at a significance level of $p<.05$ unless otherwise indicated. Errors constituted $2.2 \%$ of the color-naming data. Mean latencies and percent errors to conflict and neutral trials are presented in Table 1. All errors and response times more than $3 S D$ from a participant's mean were treated as missing data and excluded from the analyses. Errors and outliers together constituted approximately $4 \%$ of the data. Span (low vs. high) was a between-participants factor, whereas proportion (low- vs. high-proportion), trial (conflict vs. neutral), and block order were within-participants factors. We found no reliable effects involving block order; therefore, we dropped this factor from the analyses. The reported analyses were, therefore, 2 (span) $\times 2$ (proportion) analyses of variance (ANOVAs).

Analysis of the error data revealed no reliable effects (all $F \mathrm{~s}<1$ ). In contrast, analysis of the color-naming latencies revealed a reliable effect of trial $[F(1,18)=211.80$, $\left.M S_{\mathrm{e}}=166,376\right]$. This effect was modified by reliable proportion $\times$ trial and span $\times$ proportion $\times$ trial interactions $\left[F(1,18)=17.93, M S_{\mathrm{e}}=32,822\right.$, and $F(1,18)=$ $7.81, M S_{\mathrm{e}}=14,306$, respectively $]$.

Follow-up analyses revealed different patterns of response times for the high- and low-span individuals. High-span individuals exhibited substantial Stroop interference in the low-proportion condition, responding much more slowly on conflict than on neutral trials $[F(1,18)=79.10]$, whereas they showed little interference in the high-proportion condition $[F(1,18)=1.41]$. In contrast, low-span individuals showed substantial Stroop interference in both the high-and low-proportion conditions $[F(1,18)=80.46$ and $F(1,13)=24.82]$.

The quasi-experimental design that we used in this experiment has several drawbacks. First, the separation of individuals into extreme groups (high and low span) may have exaggerated the effect of working-memory capacity on Stroop interference. Second, this separation was based on a somewhat arbitrary criterion: top and bottom thirds of the reading-span distribution. Finally, the experiment involved relatively few participants and exclusion of a third of our participants reduced our sample size even further. To address these concerns, we examined the full data set in a regression analysis. For each participant, we computed an interference score that was the amount of interference experienced in the low-proportion condition minus the amount of interference experienced in the high-proportion condition. Thus, the higher the in- 
terference score, the greater the difference in the amount of interference experienced in the low-proportion relative to the high-proportion condition. We found a reliable relation between reading span and interference $[\beta=$ $.46, t(1,28)=2.10]$. The difference in interference between the high-and low-proportion conditions increased as a function of reading span. High-span individuals experienced much less interference in the high-proportion than in the low-proportion condition, whereas low-span individuals experienced comparable interference in the two conditions. These results are consistent with the ANOVA results.

Are young adults with low working-memory spans particularly susceptible to Stroop interference? The answer to this question depends on the context in which participants are tested. Overall, high- and low-span individuals showed similar levels of interference (115 and $130 \mathrm{msec}$ of interference for high- and low-span individuals, respectively). Substantial differences in the amount of interference arose, however, when the proportion of conflict trials was varied. Low-span individuals showed substantial Stroop interference irrespective of the proportion of conflict trials. High-span individuals, in contrast, showed substantial interference only in the lowproportion condition.

We had hypothesized that the large number of conflict trials in the high-proportion condition might encourage high-span individuals to adopt a reading-suppression strategy. Although the data are consistent with this hypothesis, they reveal little about the nature of such a strategy. The goal of Experiment 2 was to investigate how high-span individuals were able to minimize Stroop interference in the high-proportion condition.

\section{EXPERIMENT 2}

Previous research has demonstrated that Stroop interference can be greatly reduced through practice (Dulaney \& Rogers, 1994; Ellis \& Dulaney, 1991; MacLeod, 1998; MacLeod \& Dunbar, 1988). This effect has been attributed to the development of a reading suppression strategy. Reading suppression may underlie the resistance of high-span individuals to Stroop interference in the highproportion condition. It is very unclear, however, exactly what is meant by reading suppression (Dulaney \& Rogers, 1994; Ellis \& Dulaney, 1991). Do high-span individuals actually suppress the process by which a visual stimulus is mapped to a semantic representation-that is, suppression of reading, per se? Alternatively, do they read the word sufficiently to activate its semantic representation and then quickly suppress the activated representation? The goal in this experiment was to explore these two possibilities.

Recent research suggests one means by which reading suppression might occur. Stroop interference is dramatically reduced when attention is redirected from a semanticlevel analysis to a more perceptual one (Besner \& Stolz, 1999a, 1999b; Besner, Stolz, \& Boutilier, 1997). Besner et al. demonstrated this in an experiment comparing
Stroop interference in the standard task (e.g., all of the letters in the word green were printed in red) with a version of the task in which only a single letter was colored. In both cases, participants were told to ignore the word and to name the ink color. Stroop interference was absent when participants were asked to name the single colored letter embedded in the incongruent word. Besner and Stolz (1999a, 1999b) argued that semantic-level analysis is the default mental set of skilled readers. The default set can be overridden, however, by contexts that direct attention to other levels of analysis (e.g., the letter level). Such redirection of attention may be the means by which high-span individuals reduce their susceptibility to Stroop interference. If they spontaneously adopted such a strategy, they would experience no interference because the meaning of the word would never be computed.

An alternative explanation of the resistance of highspan individuals to Stroop interference is that they inhibited or suppressed the semantic representation of the irrelevant word. That is, the irrelevant word received normal semantic analysis; the semantic representation was then inhibited to reduce competition with the color name. This would be consistent with claims by Engle and his colleagues that high-span individuals are better able than low-span individuals to inhibit or suppress interfering information (Conway \& Engle, 1994; Engle et al., 1995; Rosen \& Engle, 1997, 1998). If inhibition underlies the resistance of high-span individuals to interference, then the data in Experiment 1 suggest that such inhibition is under contextual control. High-span individuals were resistant to interference only in the high-proportion condition.

These two possibilities might be discriminated by examining Stroop interference in combination with a negative priming manipulation. Negative priming is observed in selective attention tasks (for reviews, see Fox, 1995; May, Kane, \& Hasher, 1995). Participants are asked to attend and respond selectively to a target, while simultaneously ignoring a distractor. Responses are slowed when the distractor on one trial becomes the target on the subsequent trial. The negative priming effect was first documented in the Stroop task (Dalrymple-Alford \& Budayr, 1966; Lowe, 1979; Neill, 1977; Neill \& Westberry, 1987). Negative priming is observed when the tobe-ignored word on one trial (the prime trial) turns out to the to-be-named color on the next trial (the target trial).

One prominent account of negative priming is that an inhibitory mechanism underlies the effect (Neill, 1977; Neill \& Westberry, 1987; Tipper, 1985; Tipper \& Baylis, 1987; Tipper \& Cranston, 1985). During, or shortly after, selection of the target on the prime trial, inhibition operates either to suppress the activation state of the distractor representation or to block the translation of this representation into a response. Either of these possibilities results in slow responses when the distractor becomes the target on the next trial.

If we assume that negative priming results from an inhibitory mechanism (an assumption that we will examine later), then we can use a negative-priming manipula- 
tion in combination with the Stroop task to determine whether high-span individuals reduce Stroop interference by inhibiting the distracting information or by redirecting attention to a lower level, perceptual analysis of the target. If they compute the meaning of the distracting word and subsequently inhibit it, then the semantic representation should be difficult to reactivate for some short period of time. Thus, inhibition would predict substantial negative priming, slow responses when the tobe-ignored word on the prime trial turns out to be the tobe-named color on the target trial (e.g., green in blue print is followed by red in green print). In contrast, if they divert attention to a perceptual rather than a semantic level of analysis (Besner \& Stolz, 1999a, 1999b; Besner et al., 1997), then word meanings would not be activated and inhibition would be unnecessary. In the absence of inhibition, response difficulty should not occur on the negative priming trials.

We examined the performance of high- and low-span individuals on trials in which the to-be-named color was the to-be-ignored word on the previous trial. The procedure was a replication of Experiment 1 using only the highproportion condition. The conflict trials were arranged in pairs. Some pairs were related so that the irrelevant word on the prime trial was the to-be-named word on the target trial (negative priming trials). Other pairs involved no relation between the prime and the target (conflict trials). If high-span individuals actually suppress the semantic activation of the irrelevant word to maximize performance on the color-naming task, then their level of interference on conflict trials should be low (i.e., they should experience minimal Stroop interference). This should not be true, however, on the negative priming trials. On these trials, high-span individuals should show impaired performance (i.e., they should experience substantial negative priming) because inhibition of the word meaning on the prime trial should lead to difficulty in accessing this information on the target trial. Alternatively, high-span individuals may ignore a semantic level of analysis. If so, then they should experience little Stroop interference on conflict trials because they should detect no semantic conflict between prime and target trials. Likewise, they should experience little difficulty on negative priming trials because the word meaning on the prime trial was never activated and thus was never inhibited.

\section{Method}

Participants. The participants were 75 undergraduate psychology students who received course credit for their participation. High- and low-span participants were identified via the procedure described in Experiment 1. High-span individuals had scores that ranged from 41 to $57(M=44.88, n=25)$. Low-span individuals had scores that ranged from 19 to $32(M=25.96, n=25)$.

Materials and Procedure. The stimuli were divided into two blocks of 100 trials each. Each block contained 20 neutral trials and 80 color-word trials arranged in prime-target pairs. Half of the pairs were related in that the to-be-ignored word on the prime trial was the to-be-named color on the target trial (negative priming trials) and half were unrelated (conflict trials). Trial pairs of the two types were randomly intermingled. Colors and words appeared in ap- proximately equal numbers of times in the two blocks. A separate block of 20 trials ( 10 conflict and 10 neutral) was used as a practice set.

The procedure was the same as that described in Experiment 1 except that participants received the reading-span test and the Stroop task in the same session. Block order was randomized, as were the neutral and prime-target trials within each block.

\section{Results and Discussion}

Mean latencies and percent errors are presented in Table 2 . We performed 2 (span) $\times 3$ (trial) ANOVAs on the accuracy and response time data, collapsing over block. Errors constituted $2.7 \%$ of the color-naming data. Errors and outliers together constituted $4.1 \%$ of the data. Span (low vs. high) was a between-participants factor, whereas trial (neutral vs. conflict vs. negative priming) was a within-participants factor.

Analysis of the error data revealed no reliable effects (all $\left.F_{\mathrm{S}}<1\right)$. In contrast, analysis of the color-naming latencies revealed reliable effects of trial and span $[F(2,96)=$ $194.17, M S_{\mathrm{e}}=2,049$ and $F(1,48)=8.52, M S_{\mathrm{e}}=50,044$, respectively]. These effects were modified by a reliable span $\times$ trial interaction $\left[F(2,96)=43.75, M S_{\mathrm{e}}=2,049\right]$. High-span individuals showed little difference in their response to conflict and neutral trials $(F<1)$, replicating the pattern in Experiment 1. They exhibited substantial negative priming, responding more slowly on the negative priming trials than on the conflict trials $[F(2,96)=$ 201.61]. They also responded more slowly on negative priming trials than on neutral trials $[F(2,96)=197.60]$. In contrast, low-span individuals showed substantial interference on both conflict and negative priming trials, responding much more slowly on these trials than on neutral trials $[F(2,96)=122.97$ and $F(2,96)=185.37]$. They also showed reliable negative priming $[F(2,96)=$ 6.38], although the magnitude of the effect was much smaller among low- than among high-span individuals.

We also conducted a regression analysis on the full data set as described in Experiment 1. We computed an interference score that was the amount of interference experienced on negative priming trials relative to conflict trials. This score reflects the increase in interference due to negative priming. We found a strong relation between reading span and negative priming $[\beta=.62, t(1,63)=6.28]$;

Table 2

Mean Response Times (RTs, in Milliseconds), Percent Errors (PEs), and Standard Deviations to Neutral, Conflict, and Negative Priming (NP) Trials in Experiment 2

\begin{tabular}{|c|c|c|c|c|c|c|}
\hline \multirow[b]{3}{*}{ Trial Type } & \multicolumn{6}{|c|}{ Working-Memory Span } \\
\hline & \multicolumn{3}{|c|}{ High } & \multicolumn{3}{|c|}{ Low } \\
\hline & RT & $\mathrm{PE}$ & $S D$ & RT & $\mathrm{PE}$ & $S D$ \\
\hline Neutral & 763 & 2.2 & 97.38 & 824 & 2.4 & 115.72 \\
\hline Conflict & 761 & 2.8 & 136.09 & 966 & 2.6 & 144.22 \\
\hline NP & 943 & 3.3 & 145.24 & 998 & 3.0 & 158.12 \\
\hline $\begin{array}{l}\text { Difference } \\
\quad \text { (Conflict-Neutral) }\end{array}$ & -2 & 0.6 & & 142 & 0.2 & \\
\hline $\begin{array}{l}\text { Difference } \\
\qquad \text { (NP-Conflict) }\end{array}$ & 182 & 0.5 & & 32 & 0.4 & \\
\hline
\end{tabular}


negative priming increased as a function of workingmemory span.

This experiment was conducted to examine the means by which high-span individuals were able to minimize Stroop interference in the context of frequent conflict trials. Our results are inconsistent with the hypothesis that they abandoned a default mental set involving the semantic analysis of words in favor of analysis at lower, perceptual, levels. They clearly computed the meaning of the irrelevant word because they experienced substantial difficulty when the to-be-ignored word on the prime trial was the to-be-named word on the target trial. Rather, our negative priming results are consistent with an inhibitory hypothesis. High-span individuals computed the meaning of the irrelevant word and then inhibited it. As a consequence, they exhibited substantial interference when a subsequent trial required retrieval of the inhibited representation. This explanation of our results, however, relies on an inhibitory account of the negative priming effect. We discuss an alternative, noninhibitory account of our findings in the next section.

\section{GENERAL DISCUSSION}

Our results, like those reported by Besner and his colleagues (Besner \& Stolz, 1999a, 1999b), demonstrate the importance of context in modulating the extent to which participants experience Stroop interference. Highspan individuals showed less interference than did lowspan individuals, but only in the context of frequent conflict trials. This result has implications for understanding the relation between working-memory capacity and the ability to overcome interference or response competition. Performance of the high-span individuals in the low-proportion condition of Experiment 1 suggested that they were as vulnerable to interference from irrelevant information as were low-span individuals. Unlike lowspan individuals, however, they were able to engage a strategy for overcoming such interference when the strategy had high utility, as it did in the high-proportion condition.

Experiment 2 provided some preliminary information about the nature of a reading suppression strategy. Reading suppression did not appear to involve suppression of the word recognition process, per se. High-span individuals showed a large negative priming effect; that is, they were very slow to respond on trials in which the to-benamed color was the irrelevant word on the previous trial. Thus, the act of ignoring the irrelevant word on the prime trial had consequences for responding on the target trial.

Thus far we have interpreted our negative priming results as consistent with the operation of an inhibitory mechanism. According to this account, negative priming is related to the ability of high-span individuals to reduce Stroop interference. When the proportion of conflict trials is high, they employ a suppression strategy. This results in less interference on conflict trials, but also results in negative priming when the irrelevant word on the prime trial is the to-be-named color on the target trial.

Although this is a parsimonious explanation of our results, it relies on an inhibitory account of the negative priming effect. Inhibitory accounts of negative priming, however, have been challenged in recent years by a class of explanations that attributes negative priming to the operation of memory retrieval processes (Milliken, Joordens, Merikle, \& Seiffert, 1998; Neill \& Valdes, 1992; Neill, Valdes, Terry, \& Gorfein, 1992). Neill and his colleagues have proposed one such explanation (Neill \& Valdes, 1992; Neill et al., 1992). According to their episodic retrieval theory, presentation of a stimulus automatically results in retrieval of the most recent episode involving that stimulus, including information about the attributes of the stimulus and any response that was associated with it. If the retrieved stimulus has been recently ignored, then retrieval of that information may interfere with current response selection. According to this account, individual differences in negative priming arise not from differences in the ability to inhibit distracting information, but from differences in memory encoding or retrieval.

The episodic retrieval account can explain why lowspan individuals exhibited less negative priming than did high-span individuals (Experiment 2). Low-span individuals encode information or retrieve it less efficiently than do high-span individuals; thus, they experience less interference on negative priming trials. Can this account also explain why high-span individuals experience less Stroop interference than do low-span individuals when the proportion of conflict trials is high (Experiment 1)? The answer to this question is not obvious. It may be that negative priming and the reduction in Stroop interference observed among high-span individuals are unrelated phenomena. Alternatively, the memory retrieval processes that lead to selection difficulty on some trials (negative priming) may be balanced by retrieval processes that lead to selection facilitation on other trials, resulting in an overall reduction in interference. The results of our experiments provide little insight into these issues, but clearly present an interesting empirical puzzle for the episodic retrieval account.

One aspect of the performance of low-span individuals in Experiment 2 is notable. They showed much less negative priming than did high-span individuals. This finding is consistent with recent reports of individual differences in the negative priming effect. These studies have shown that certain groups-in particular, Alzheimer's patients, schizophrenics, children, and older adultsoften show reduced negative priming (Cohen \& ServanSchreiber, 1992; Dempster, 1992; Hasher \& Zacks, 1988; Simone \& Baylis, 1997). Most applicable to the results presented here is a recent study by Conway, Tuholski, Shisler, and Engle (1999). They examined individual differences in negative priming as a function of individual differences in working-memory capacity. Their findings were very similar to those reported here; high-span indi- 
viduals exhibited much more negative priming than did low-span individuals.

In summary, our experiments showed that high-span individuals adopt a strategy to overcome Stroop interference when such a strategy is encouraged by the context of the experiment. Moreover, they show a much larger negative priming effect than do low-span individuals. Both findings are consistent with the hypothesis that individual differences in working-memory capacity are related to differences in the ability to inhibit taskirrelevant information. Further research will be necessary to determine whether individual differences in memory retrieval processes can also provide a full account of these findings.

\section{REFERENCES}

Baddeley, A. D., \& Hitch, G. J. (1974). Working memory. In G. H. Bower (Ed.), The psychology of learning and motivation: Advances in research and theory (Vol. 8, pp. 47-89). New York: Academic Press.

Besner, D., \& Stolz, J. A. (1999a). Unconsciously controlled processing: The Stroop effect reconsidered. Psychonomic Bulletin \& Review, 6, 449-455.

Besner, D., \& Stolz, J. A. (1999b). What kind of attention modulates the Stroop effect? Psychonomic Bulletin \& Review, 6, 99-104.

Besner, D., Stolz, J. A., \& Boutilier, C. (1997). The Stroop effect and the myth of automaticity. Psychonomic Bulletin \& Review, 4, 221-225.

Cohen, J. D., \& Servan-Schreiber, D. (1992). Context, cortex, and dopamine: A connectionist approach to behavior and biology in schizophrenia. Psychological Review, 99, 45-77.

Cohn, N. B., Dustman, R. E., \& Bradford, D. C. (1984). Age-related decrements in Stroop color test performance. Journal of Clinical Psychology, 40, 1244-1250.

Comalli, P. E., JR., WAPNer, S., \& Werner, H. (1962). Interference effects of Stroop color-word test in childhood, adulthood, and aging. Journal of Genetic Psychology, 100, 47-53.

Conway, A. R. A., \& ENGle, R. W. (1994). Working memory and retrieval: A resource-dependent inhibition model. Journal of Experimental Psychology: General, 123, 354-373.

Conway, A. R. A., Tuholski, S. W., Shisler, R. J., \& Engle, R. W. (1999). The effect of memory load on negative priming: An individual differences investigation. Memory \& Cognition, 27, 1042-1050.

Cowan, N. (1988). Evolving conceptions of memory storage, selective attention, and their mutual constraints within the human information processing system. Psychological Bulletin, 104, 163-191.

Cowan, N. (1995). Attention and memory: An integrated framework. New York: Oxford University Press.

Dalrymple-Alford, E. C., \& Budayr, B. (1966). Examination of some aspects of the Stroop color-word test. Perceptual \& Motor Skills, 23, 1211-1214.

Daneman, M., \& Carpenter, P. A. (1980). Individual differences in working memory and reading. Journal of Verbal Learning \& Verbal Behavior, 19, 450-466.

Daneman, M., \& CARPenter, P. A. (1983). Individual differences in integrating information between and within sentences. Journal of Experimental Psychology: Learning, Memory, \& Cognition, 9, 561-584.

DEMPSTER, F. N. (1992). The rise and fall of the inhibitory mechanism: Toward a unified theory of cognitive development and aging. Developmental Review, 12, 45-75.

Dulaney, C. L., \& Rogers, W. A. (1994). Mechanisms underlying reduction in Stroop interference with practice for young and old adults. Journal of Experimental Psychology: Learning, Memory, \& Cognition, 20, 470-484.

Ellis, N. R, \& Dulaney, C. L. (1991). Further evidence for cognitive inertia of persons with mental retardation. American Journal on Mental Retardation, 95, 613-621

Engle, R. W., CANToR, J., \& CARullo, J. J. (1992). Individual differ- ences in working memory and comprehension: A test of four hypotheses. Journal of Experimental Psychology: Learning, Memory, \& Cognition, 18, 972-992.

Engle, R. W., Carullo, J. J., \& Collins, K. W. (1991). Individual differences in working memory for comprehension and following directions. Journal of Educational Research, 84, 253-262.

Engle, R. W., Conway, A. R. A., Tuholski, S. W., \& Shisler, R. J. (1995). A resource account of inhibition. Psychological Science, 6 , 122-125.

Engle, R. W., Kane, M. J., \& Tuholski, S. W. (1999). Individual differences in working memory capacity and what they tell us about controlled attention, general fluid intelligence, and functions of the prefrontal cortex. In A. Miyake \& P. Shah (Eds.), Models of working memory: Mechanisms of active maintenance and executive control (pp. 102-134). New York: Cambridge University Press.

Engle, R. W., Tuholski, S. W., Laughlin, J. E., \& Conway, A. R. A. (1999). Working memory, short-term memory, and general fluid intelligence: A latent-variable approach. Journal of Experimental Psychology: General, 128, 309-331.

Ericsson, K. A., \& Delaney, P. F. (1999). Long-term working memory as an alternative to capacity models of working memory in everyday skilled performance. In A. Miyake \& P. Shah (Eds.), Models of working memory: Mechanisms of active maintenance and executive control (pp. 257-297). New York: Cambridge University Press.

ERICSSON, K. A., \& KinTSCH, W. (1995). Long-term working memory. Psychological Review, 102, 211-245.

Fox, E. (1995). Negative priming from ignored distractors in visual selection: A review. Psychonomic Bulletin \& Review, 2, 145-173.

Gernsbacher, M. A., \& FAust, M. (1995). Skilled suppression. In F. N. Dempster (Ed.), Interference and inhibition in cognition (pp. 295327). San Diego: Academic Press.

HASHER, L., \& ZACKS, R. T. (1988). Working memory, comprehension, and aging: A review and a new view. In G. H. Bower (Ed.), The psychology of learning and motivation: Advances in research and theory (Vol. 22, pp. 193-225). San Diego: Academic Press.

Just, M. A., \& CARPENTER, P. A. (1992). A capacity theory of comprehension: Individual differences in working memory. Psychological Review, 99, 122-149.

Kieras, D. E., Meyer, D. E., Mueller, S., \& Seymour, T. (1999). Insights into working memory from the perspective of the EPIC architecture for modeling skilled perceptual-motor and cognitive human performance. In A. Miyake \& P. Shah (Eds.), Models of working memory: Mechanisms of active maintenance and executive control (pp. 183-223). New York: Cambridge University Press.

KING, J., \& JUST, M. A. (1991). Individual differences in syntactic processing: The role of working memory. Journal of Memory \& Language, 30, 580-602.

KLapp, S. T., Marshburn, E. A., \& Lester, P. T. (1983). Short-term memory does not involve the "working memory" of information processing: The demise of a common assumption. Journal of Experimental Psychology: General, 112, 240-264.

Kyllonen, P. C., \& Christal, R. E. (1990). Reasoning ability is (little more than) working-memory capacity? Intelligence, 14, 389-433.

Ky llonen, P. C., \& Stephens, D. L. (1990). Cognitive abilities as determinants of success in acquiring logic skill. Learning \& Individual Differences, 2, 129-160.

Lovett, M. C., Reder, L. M., \& Lebiere, C. (1999). Modeling working memory in a unified architecture: An ACT-R perspective. In A. Miyake \& P. Shah (Eds.), Models of working memory: Mechanisms of active maintenance and executive control (pp. 135-182). New York: Cambridge University Press.

LowE, D. G. (1979). Strategies, content, and the mechanisms of response inhibition. Memory \& Cognition, 7, 382-389.

MacDonald, M. C., Just, M. A., \& CARPenter, P. A. (1992). Working memory constraints on the processing of syntactic ambiguity. Cognitive Psychology, 24, 56-98.

MacLeod, C. M. (1991). Half a century of research on the Stroop effect: An integrative review. Psychological Bulletin, 109, 163-203.

MacLeod, C. M. (1998). Training on integrated versus separated Stroop tasks: The progression of interference and facilitation. Memory \& Cognition, 26, 201-211. 
MacLeod, C. M., \& Dunbar, K. (1988). Training and Stroop-like interference: Evidence for a continuum of automaticity. Journal of Experimental Psychology: Learning, Memory, \& Cognition, 14, 126-135.

May, C. P., Kane, M. J., \& HASher, L. (1995). Determinants of negative priming. Psychological Bulletin,118, 35-54.

Milliken, B., Joordens, S., Merikle, P. M., \& Seiffert, A. E. (1998). Selective attention: A reevaluation of the implications of negative priming. Psychological Review, 105, 203-229.

NeILL, W. T. (1977). Inhibition and facilitation processes in selective attention. Journal of Experimental Psychology: Human Perception \& Performance, 3, 444-450.

NeILL, W. T., \& VAldes, L. A. (1992). Persistence of negative priming: Steady-state or decay? Journal of Experimental Psychology: Learning, Memory, \& Cognition, 18, 565-576.

Neill, W. T., Valdes, L. A., Terry, D. M., \& Gorfein, D. S. (1992). Persistence of negative priming: II. Evidence for episodic trace retrieval. Journal of Experimental Psychology: Learning, Memory, \& Cognition, 18, 993-1000.

Neill, W. T., \& Westberry, R. L. (1987). Selective attention and the suppression of cognitive noise. Journal of Experimental Psychology: Learning, Memory, \& Cognition, 13, 237-334.

Panek, P. E., Rush, M. C., \& Slade, L. A. (1984). Locus of the ageStroop interference relationship. Journal of Genetic Psychology, 145, 209-216.

Pearlmutter, N. J., \& MacDonald, M. C. (1995). Individual differences and probabilistic constraints in syntactic ambiguity resolution. Journal of Memory \& Language, 34, 521-542.

Posner, M. I., \& SNyder, C. R. R. (1975). Attention and cognitive control. In R. L. Solso (Ed.), Information processing and cognition: The Loyola Symposium (pp. 55-85). Hillsdale, NJ: Erlbaum.

Rosen, V. M., \& ENGLE, R. W. (1997). The role of working memory capacity in retrieval. Journal of Experimental Psychology: General, 126, 211-227.

Rosen, V. M., \& ENGLE, R. W. (1998). Working memory capacity and suppression. Journal of Memory \& Language, 39, 418-436.
SAlthouse, T. A. (1996). The processing-speed theory of adult age differences in cognition. Psychological Review, 103, 403-428.

SCHNEIDER, W. (1999). Working memory in a multilevel hybrid connectionist control architecture (CAP2). In A. Miyake \& P. Shah (Eds.), Models of working memory: Mechanisms of active maintenance and executive control (pp. 340-374). New York: Cambridge University Press.

Shute, V. J. (1991). Who is likely to acquire programming skills? Journal of Educational Computing Research, 7, 1-24.

Simone, P. M., \& BAY Lis, G. C. (1997). Selective attention in a reaching task: Effect of normal aging and Alzheimer's disease. Journal of Experimental Psychology: Human Perception \& Performance, 23, 595-608.

Stoltzfus, E. R., Hasher, L., \& Zacks, R. T. (1996). Working memory and aging: Current status of the inhibitory view. In J. T. E. Richardson, R. W. Engle, L. Hasher, R. H. Logic, E. R. Stoltzfus, \& R. T. Zacks (Eds.), Working memory and human cognition (pp. 6688). New York: Oxford University Press.

TipPER, S. P. (1985). The negative priming effect: Inhibitory effects of ignored primes. Quarterly Journal of Experimental Psychology, 37A, 571-590.

Tipper, S. P., \& Bay Lis, G. C. (1987). Individual differences in selective attention: The relation of priming and interference to cognitive failure. Personality \& Individual Differences, 8, 667-675.

Tipper, S. P., \& Cranston, M. (1985). Selective attention and priming: Inhibitory and facilitatory effects of ignored primes. Quarterly Journal of Experimental Psychology, 37A, 591-611.

Young, R. M., \& LewIS, R. L. (1999). The Soar cognitive architecture and human working memory. In A. Miyake \& P. Shah (Eds.), Models of working memory: Mechanisms of active maintenance and executive control (pp. 224-256). New York: Cambridge University Press.

(Manuscript received September 27, 2000; revision accepted for publication July 30, 2001.) 